\title{
"How do I get From Here to There?" An Examination of Ph.D. Science Students' Career Preparation and Decision Making
}

\author{
Heather Thiry and Sandra L. Laursen \\ Ethnography \& Evaluation Research, \\ University of Colorado, Boulder, CO, United States \\ heather.thiry@colorado.edu sandra.laursen@colorado.edu \\ Heidi G. Loshbaugh \\ Center for Math \& Science, \\ Community College of Denver, Denver, CO, United States \\ heidi.loshbaugh@ccd.edu
}

\begin{abstract}
Drawing on developmental networks theory, this qualitative research study explores the professional preparation and career decision-making processes of doctoral students in the sciences. The study is based on 95 semi-structured interviews with informants at three research universities in the United States. Though many students were interested in non-academic career tracks, they were largely unaware of the breadth of their choices or how to best prepare for these careers. Unable to cultivate networks in non-academic careers, many students turned to peers to fill the career development gap. Due to their lack of knowledge about career options, among other factors, students often delayed selecting and preparing for careers until the end of their graduate studies. Implications for doctoral education practice are discussed.
\end{abstract}

Keywords: Ph.D. students, career preparation, decision-making processes, doctoral students, science students

\section{Introduction}

The global scientific workforce is undergoing dramatic changes, yet the traditional model of doctoral education in the sciences remains stubbornly entrenched. To be sure, the apprenticeship model is successful in preparing students to be independent scientific researchers, yet researchers,

Material published as part of this publication, either on-line or in print, is copyrighted by the Informing Science Institute. Permission to make digital or paper copy of part or all of these works for personal or classroom use is granted without fee provided that the copies are not made or distributed for profit or commercial advantage AND that copies 1) bear this notice in full and 2) give the full citation on the first page. It is permissible to abstract these works so long as credit is given. To copy in all other cases or to republish or to post on a server or to redistribute to lists requires specific permission and payment of a fee. Contact Publisher@InformingScience.org to request redistribution permission. policymakers, and educators have voiced concerns for years about doctoral students' lack of professional preparation (American Association of Universities (AAU), 1998; Golde \& Dore, 2001; Nerad, Rudd, Morrison, \& Homer, 2006; Nyquist, 2002; Taylor, 2006; Wendler et al., 2012). Scholars have highlighted the mismatch between doctoral students' training and workforce realities (Golde \& Dore, 2001), citing 
the lack of preparation for $21^{\text {st }}$-century jobs in areas such as communication, teamwork, teaching, and leadership skills. Moreover, economic pressures, demographic trends, and the need for workers in emerging fields have influenced the nature, characteristics, and composition of the scientific workforce (National Science Board (NSB), 2012). Although the long-standing apprenticeship model of doctoral education emphasizes preparation for the professoriate, in fact, more scientists are now employed by business than by universities or government (Suresh, 2011).

Shaped, in part, by these changes in the economy and workforce, long-term job growth in the sciences is not monolithic, but varies by nation and by field. A few sectors, such as biochemistry and biotechnology in the US and renewable energy and information technologies in the EU, are projected to experience faster than average growth in the coming decade (Bureau of Labor Statistics (BLS), 2012; European Commission, 2012). In contrast, other scientific sectors are expected to experience average, or even below-average growth. Jobs for chemists and materials scientists - the subjects of this study - are projected to experience slow growth in the coming decade in both the US and Australia (Australian Government, 2012; BLS, 2012). One common thread does transcend national borders; in many countries, the number of recent scientific doctorates in some fields may exceed the supply of available and appropriate jobs, at least by traditional definitions (American Chemical Society (ACS), 2012; Cyranoski, Gilbert \&Ledford, 2011; Neumann $\&$ Tan, 2011).

Although an increasing number of scientific doctorates are employed outside of the professoriate, the nature of scientific work within academe is changing, too. The recent economic downtown is expected to have a long-lasting impact on higher education in the US with reduced institutional funding, diminished faculty salaries, and increased numbers of non-tenure-track faculty positions (American Association of University Professors (AAUP), 2011). Internationally, there has been a decline in the number of academic positions available for doctoral recipients (AAUP, 2011; Neuman \& Tan, 2011), and recent scientific doctorates in the US are increasingly turning to temporary postdoctoral research positions for their first employment (BLS, 2012). The impact of these changes on the practice of science in academe is not yet clear; but the outcomes for individual lives and careers seem detrimental as these positions offer lower pay and fewer benefits than permanent academic positions.

Commensurate with the realities of the scientific labor market, most doctoral students in scientific fields do not aspire to or pursue academic careers (Fox \&Stephan, 2001; Nerad et al., 2006; NSB, 2012; Sauermann \& Roach, 2012), yet "alternative" career paths, such as those in education or public outreach are often discouraged by science faculty (Connolly, 2011; Janke \& Colbeck, 2008; Laursen, Thiry, \& Liston, 2012; Thiry, Laursen, \& Liston, 2007). Experiences that supplement doctoral research and coursework, such as professional development trainings, workshops, or internships, are beneficial in developing students' skills and clarifying their career paths (Bouwma-Gearhart, Millar, Barger, \& Connolly, 2007; Laursen et al., 2012;) and are recommended in calls for doctoral reform (AAU, 1998; Golde \& Dore, 2001; Nerad et al., 2006; Nyquist, 2002; Taylor, 2006) - yet these opportunities are not widely available. Recent research has affirmed the need for more explicit professional preparation in doctoral education (Austin, 2002; Austin \& McDaniels, 2006; Golde, 2008; Golde \& Dore, 2001; Kuck, Marzabadi, Buckner, \& Nolan, 2007).

Thus, the scientific workforce is rapidly changing and career prospects for doctoral scientists are muddled: projections vary by field, occupational sector, and country. Doctoral recipients in some fields, such as the field of chemistry investigated in this study, or sectors, such as higher education, may struggle to find suitable jobs in the face of declining job prospects. For these reasons, doctoral students' awareness of non-academic careers and preparation for the $21^{\text {st }}$ century global workforce is a pressing concern. Students and doctoral advisors can no longer assume that an appropriate and desirable job will appear at the end of doctoral studies. 
It is clear that both pragmatic realities and research on career development speak to the need for more informed career preparation for doctoral students in the sciences. Yet we still know little about how doctoral students learn about and prepare for future careers. Doctoral students' nonacademic career pathways have also been relatively uninvestigated (Baker \& Pifer, 2014; Wendler et al., 2012). Some studies have focused on students' beliefs about academic careers (Austin, 2002; Bieber \& Worley, 2006), while others have investigated students' professional socialization within disciplinary and departmental contexts (Gardner, 2007). Instead, this study explores doctoral students' knowledge about careers, including non-academic careers, the sources of this knowledge, and their influence on students' career development.

\section{Developmental Networks and Professional Learning in Doctoral Education}

The nature of academic disciplines and scientific professions is shifting and doctoral students must seek a wide range of experiences to help them learn about and prepare for careers (Antony, 2002). We turn to developmental networks theory (see Higgins \& Kram, 2001; Sweitzer, 2009) to explore the sources of doctoral students' learning about careers, particularly the role that social networks play in their knowledge about career options and their professional preparation. Higgins and Kram (2001) originated the concept of a developmental network, defining it as the "people a protégé names as taking an active interest in and action to advance the protégé's career by providing developmental assistance" (p. 268). Developmental networks theorists have often focused on specific social interactions and relationships, especially the range (i.e., the variety of sources and contexts within networks) and the density of networks (i.e., how well the connections, or "developers," know one another) (Dobrow \& Higgins, 2005; Higgins \& Kram, 2001). Recent research has examined the role of "distant, unmet, or imaginary figures" in students' developmental networks (Dobrow, Chandler, Murphy, \& Kram, 2012), thus broadening the concept to include short-term connections, virtual relationships, media images, and other social phenomena that may influence students' professional development. In this study, we focus on the range of students' networks, especially the variety of sources within their networks, rather than the density of students' networks.

Career preparation involves more than simply the acquisition of technical knowledge and disciplinary expertise. Though these elements are important aspects of the learning process, learning also involves identification with a discipline, profession, or community; in short, "becoming" a certain type of person (Lave \& Wenger, 1991; Stevens, O'Connor, Garrison, Jocuns, \& Amos, 2008). While developmental networks theory provides insight into the "developers" that influence students' career trajectories, it has focused less on the identities that are fostered through these networks, the cultural and social contexts within which these networks operate, or the role of individual agency in shaping professional learning and career paths. Recently, developmental networks theorists have begun to incorporate concepts from sociocultural theories of learning, such as agency, identity, and culture into their research (Baker \& Lattuca, 2010; Baker \& Pifer, 2014; Hopwood, 2010; McAlpine \& Lucas, 2011). The integration of developmental networks and sociocultural theories expands the theory to include the processes by which students become members of a professional community. In this study, we explore the specific developers and developmental opportunities that shape students' career trajectories, yet we also consider the role that student agency plays in students' career preparation and the cultural and social phenomena that may facilitate or constrain students' professional development.

These sociocultural constructs highlight the importance of possible selves in students' developmental trajectories. Possible selves are defined as professional identities that one may try out by observing role models, experimenting with provisional selves, and then evaluating the results (Ibarra, 1999). Professional identity development, including students' career decision-making pro- 
cesses, hinges on students' ability to experiment with possible selves and subsequently select or discard the possible selves that have been considered (Hopwood, 2010). Through this process of experimentation with a variety of possible selves, doctoral students shape their identities as professionals within their discipline. This aspect of identity development is crucial to students' trajectories as they must "begin to enact and assume the professional identity of their intended career in order to be deemed credible" (Baker \& Pifer, 2014, p. 140).

Developmental networks theory in doctoral education has most often been applied in terms of academic career preparation (Sweitzer, 2009), although the theory holds promise as a lens to examine the influence of the range of networks in students' preparation for non-academic careers. Doctoral education researchers have not yet fully explored how students construct (or not) developmental networks outside of the doctoral advisor-student relationship to learn about or prepare for careers. For these two reasons, developmental networks theory is a valuable lens to investigate doctoral students' career learning and preparation, particularly for non-academic careers.

\section{Research Design and Methodology}

Overall, this broad research study explored science doctoral students' professional learning and preparation and their career decision-making processes. We examined these fundamental issues through the perspectives of early and late-stage doctoral students, faculty research advisors, and others with knowledge of doctoral students' educational experiences.

The following research question is the focus of this paper:

What role do students' developmental networks play in their knowledge and beliefs about career options?

We explore this question through the perspectives of early-stage and late-stage doctoral students in the sciences.

\section{Disciplinary focus}

The discipline of chemistry was chosen as a site to study students' professional learning because many of the general concerns in doctoral education have been well documented in chemistry (ACS, 2012; Caserio et al., 2004; Council for Chemical Research, 2011; Kwiram, 2006). Chemistry, while a foundational scientific discipline, has become increasingly interdisciplinary, with the bulk of job growth in emerging fields such as biotechnology (ACS, 2010). Additionally, two thirds of chemists work outside academe, primarily in industry, government, or entrepreneurial ventures (ACS, 2010), and chemists are less interested in academic careers than scientists in other disciplines (Sauermann \& Roach, 2012). In fact, chemistry doctoral students' interest in the professoriate has been shown to decline during the course of their graduate studies (ACS, 2014). Because of the breadth of career paths available to doctoral chemists and the increasingly interdisciplinary nature of chemical research, chemistry was an ideal discipline in which to study doctoral students' career preparation and selection processes.

\section{Research design}

This study consisted of two phases, an initial mapping study followed by in-depth case studies of three departments. In the mapping study, we investigated the top 60 US chemistry departments to determine which departments and institutions had engaged in doctoral education reforms consistent with prior research and recommendations. In the mapping phase, we sought to explore and define the extent of such reform by determining which departments had engaged in any type of reform and what types of activities they may have undertaken. Mapping was an iterative process, an inductive qualitative research method used to gather data about a subject in context. We collected and analyzed departmental data in tandem. Early data provided us with an increasingly 
precise understanding of the nature of reform in departments and allowed us to refine later investigation.

We believed that reform-oriented departments were more likely to engage in innovative educational practices that may better prepare students for a range of careers and, thus, would make better sites for in-depth case studies. To understand how U.S. chemistry graduate departments engaged with reform, we first conducted a thorough literature review, reviewed department websites, and sought advice from over a dozen chemists and nationally recognized experts on graduate education reform. While there is no standard definition of doctoral reform, we turned to reform-oriented recommendations in the doctoral education literature to operationalize doctoral reform. Thus, we assessed departmental or institutional opportunities for teaching preparation, formal mentoring programs or training for mentors, industry seminars and internships, graduate student support groups, and doctoral student training in communications, leadership, or management skills. We then conducted interviews with department chairs, graduate program directors, and experienced faculty members of fourteen departments that appeared to have engaged in curricular, pedagogical, or programmatic reforms. This first research phase explored departments' challenges and concerns in doctoral education (Loshbaugh, Laursen, \& Thiry, 2011).

In this way, the mapping study stood alone as a descriptive study of doctoral reform in highly ranked US chemistry departments (Loshbaugh et al., 2011), yet we also used the findings to inform our selection of case study sites. From the mapping study, we chose three departments for deeper study. This number allowed us to examine similarities and differences across reformoriented departments, yet also allowed us to fully investigate the distinctive context of each site. Although qualitative research is inherently exploratory and descriptive and not usually designed to be generalizable, the inclusion of only three institutional sites does hamper the wider applicability of our findings.

Departments were chosen based on a number of factors, including student diversity, high levels of interdisciplinary research, positive departmental climate, and prior participation in doctoral reform initiatives. We measured student diversity by analyzing public data on doctoral degrees awarded in chemistry by individual departments from the Integrated Postsecondary Educational Data System (IPEDS) of the U.S. Department of Education (National Center for Educational Statistics, 2011). We conducted analyses to identify departments with above average proportions of women and students from U.S. minority groups that are underrepresented in the sciences (e.g., African Americans, Hispanics, and Native Americans), seeking departments with higher levels of diversity or those on an upward trajectory in the graduation rates of women and underrepresented minority students. We assessed levels of interdisciplinary research by analyzing department websites to identify faculty with interdisciplinary research projects or dual departmental appointments, and to ascertain whether interdisciplinarity was featured in the department's selfpresentation. We determined that a department had high levels of interdisciplinary research if multiple faculty members had dual appointments, multiple interdisciplinary research grants were housed within the department, and the departmental website emphasized interdisciplinarity. Finally, we assessed departmental climate according to mapping study interviewees' perceptions of the climate in their departments, seeking departments with consensus among interviewees that the climate was positive for faculty, staff, and students. Study sites were all relatively selective graduate chemistry programs at research-extensive universities. Two of the sites were public universities and one was private. The sites were located in the Midwest, Southern, and Eastern US.

\section{Research methods}

During campus site visits, researchers conducted open-ended, semi-structured interviews with participants. Semi-structured interviews offer systematic and consistent qualitative data collection by combining the flexibility of unstructured interviews with the directedness of surveys or struc- 
tured interviews (Schensul, Schensul \& LeCompte, 1999). The interview protocol contained a core set of open-ended questions that were based on literature reviews and our research questions. However, topics could be addressed in the order in which they came up during the interview and emerging themes were expanded and explored through probes or follow-up questions (Schensul, Schensul \& LeCompte, 1999). In this way, semi-structured interviews allowed for much deeper exploration of key constructs than structured interviews or surveys, while maintaining the consistency necessary to compare themes across the entire data set. Interview protocols addressed participants' prior career paths, future goals, and key career decision-making points; advisory relationships; professional development opportunities available in the department, on campus, and elsewhere; and the sources of students' learning - both inside and outside the departmentabout careers and being a professional in the scientific community.

Despite the advantages of interviews for capturing rich and detailed information, interviews also have drawbacks, especially when they are the sole means of data collection. Interviews elicit participants' self-reports and may not be as effective as frequent observation to investigate interactions, social and cultural processes, or everyday behaviors. To account for these shortcomings, multiple interviewers conducted and analyzed interviews because analyst triangulation is one of the primary ways to improve the robustness of qualitative research and reduce any potential bias from a single analyst (Denzin, 1978). Additionally, many students, faculty, and staff were interviewed in each department to explore issues of interest from a variety of perspectives. In this way, participants' self-reports were triangulated with the reports of other individuals (i.e., triangulation of sources) and a more comprehensive portrait could be drawn of doctoral education at each site and across sites (Denzin, 1978).

In the summer and fall of 2009, teams of two researchers conducted week-long site visits to each department. Prior to the site visits, departmental graduate education staff provided detailed lists containing doctoral students' names, e-mail addresses, entry year, sub-discipline, advisor, gender, and race/ethnicity. Stratified samples of students were drawn from these departmental records to achieve a representative sample of sub-disciplines, doctoral stage, gender, and race/ethnicity. Students were divided into early-stage and late-stage categories. Early-stage doctoral study - or phase II of doctoral study as defined by Gardner (2010a) — spans the time from entry to the Ph.D. program to achieving candidacy status, is a time when students choose a doctoral supervisor, gain research experience, and become academically and socially integrated into the department. Latestage doctoral study — or phase III as defined by Gardner - involves deeper immersion in research, changing relationships with peers and faculty, and greater focus on life after graduate school.

We over-sampled late-stage students (phase III) because they were more likely to be considering career options and developing a professional identity (Gardner, 2010a). Additionally, women and underrepresented minority students were over-sampled to ensure that their perspectives would be included in the study. Departmental chairs, graduate staff, and key university administrators were also invited to participate. The response rate by institution ranged from 50-70\%. All interviews were conducted individually, with the exception of five focus groups held with early-stage (phase II) doctoral students. The digitally recorded interviews were 45-75 minutes long and each was transcribed verbatim and submitted to NVivo 9 qualitative software for analysis.

\section{Analysis methods}

To analyze the interview data, we used domain analysis techniques developed by Spradley (1980). Three researchers reviewed transcripts, met regularly to discuss themes in the data, and developed the codebook in an iterative process. In this iterative process, codes were first generated inductively based on emerging themes and patterns based on our participants' reports, called "folk" domains by Spradley (1980). However, we also generated domains that were deductive in 
nature, or "analytic" according to Spradley (1980). In other words, analytic categories are domains that reflect theories, hypotheses, or constructs of interest to the researchers. For instance, we were interested in developmental networks and their influence on students' career paths, and thus created domain categories related to students' networks. The codes generated within these domains were largely inductive, based on students' reports about their developmental networks and sources of career learning. Additionally, we shifted from a primarily inductive approach to a more deductive approach as analysis progressed. As codes and domains emerged, we tested the categorical scheme against the existing data and generated hypotheses that we checked across the entire data set (Merriam, 2009). Some of the domains identified in our analysis were career decision points, professional development needs, sources of career learning, career planning and activities, and faculty advising behaviors and values. We examined patterns by gender, race or ethnicity, doctoral stage, and institution. Ongoing discussions among the researchers helped to refine category definitions and to assure construct validity. Comparison of researchers' interview coding enhanced inter-rater reliability.

The analytic domains discussed in this paper include developmental networks, possible selves, and agency. Using domain analysis procedures, we operationalized the concept of developmental networks by coding transcripts for students' references to role models, family of origin, and personal or professional relationships and activities that influenced students' career knowledge, beliefs, or choices. The concept of possible selves was operationalized in terms of students' knowledge (or naiveté) about career options, their beliefs about possible careers, and the career preparation behaviors that allowed them to try out certain professional roles (e.g., internships, trainings, jobs, etc.). We operationalized agency in terms of the extent of students' activity or passivity in planning and preparing for careers. The collective codes comprising these domains were examined and discussed to explore the linkages between concepts.

\section{Demographic Characteristics of Participants}

The data set for this study consisted of 95 interviews with 104 participants. Interviews were conducted with 32 late-stage students and 25 early-stage students. The demographic characteristics of student participants are summarized in Table 1. The racial/ethnic distribution of the student sample was representative of the distribution of students within the participating departments. This paper draws on interview data from early-stage and late-stage doctoral students. Interviews with 47 departmental faculty, staff, and administrators are not discussed in detail in this report but are mentioned when they offer context for, confirmation or triangulation of findings.

Table 1. Gender and racial/ethnic distribution of doctoral student sample, by graduate career stage $(n=57)$

\begin{tabular}{|l|c|c|c|c|c|c|}
\hline & \multicolumn{2}{|c|}{ Gender } & \multicolumn{4}{c|}{ Race/Ethnicity } \\
\hline & $\begin{array}{c}\text { Women } \\
(\#, \text { percentage })\end{array}$ & Men & Caucasian & $\begin{array}{c}\text { Asian- } \\
\text { American }\end{array}$ & $\begin{array}{c}\text { African- } \\
\text { American }\end{array}$ & Hispanic \\
\hline $\begin{array}{l}\text { Early-stage } \\
\text { students } \\
(\mathrm{n}=25)\end{array}$ & $\begin{array}{c}17 \\
(68 \%)\end{array}$ & $\begin{array}{c}8 \\
(32 \%)\end{array}$ & $\begin{array}{c}19 \\
(76 \%)\end{array}$ & $\begin{array}{c}2 \\
(8 \%)\end{array}$ & $\begin{array}{c}(7 \%) \\
(7 \%)\end{array}$ & 0 \\
\hline $\begin{array}{l}\text { Late-stage } \\
\text { students } \\
(\mathrm{n}=32)\end{array}$ & 18 & 14 & 25 & 0 & 5 & 2 \\
$(56 \%)$ & $(44 \%)$ & $(78 \%)$ & & & $(6 \%)$ \\
\hline
\end{tabular}




\section{Research Findings}

In this section, we describe doctoral students' awareness of career options and the sources of their learning about career paths. We discuss the influence of their developmental networks, particularly the range of their networks, on their career knowledge and beliefs, including their ability to envision themselves in potential careers. We then discuss the role of individual agency in students' career planning and decision-making processes.

\section{Doctoral Students Lack Awareness of Career Options}

A fundamental aspect of preparing for and selecting a career is the ability to envision oneself in that future career. Chemistry doctoral students, in particular, must learn about non-academic career paths because two thirds of Ph.D. chemists work outside academe (ACS, 2010). Thus, one might expect that many chemistry doctoral students would display an awareness of the array of non-academic careers available to them and might be actively weighing the advantages or drawbacks of these potential career paths. Figure 1 displays the frequency with which individual student interviewees mentioned various career options, in response to an interview inquiry about the career paths available to Ph.D. chemists.

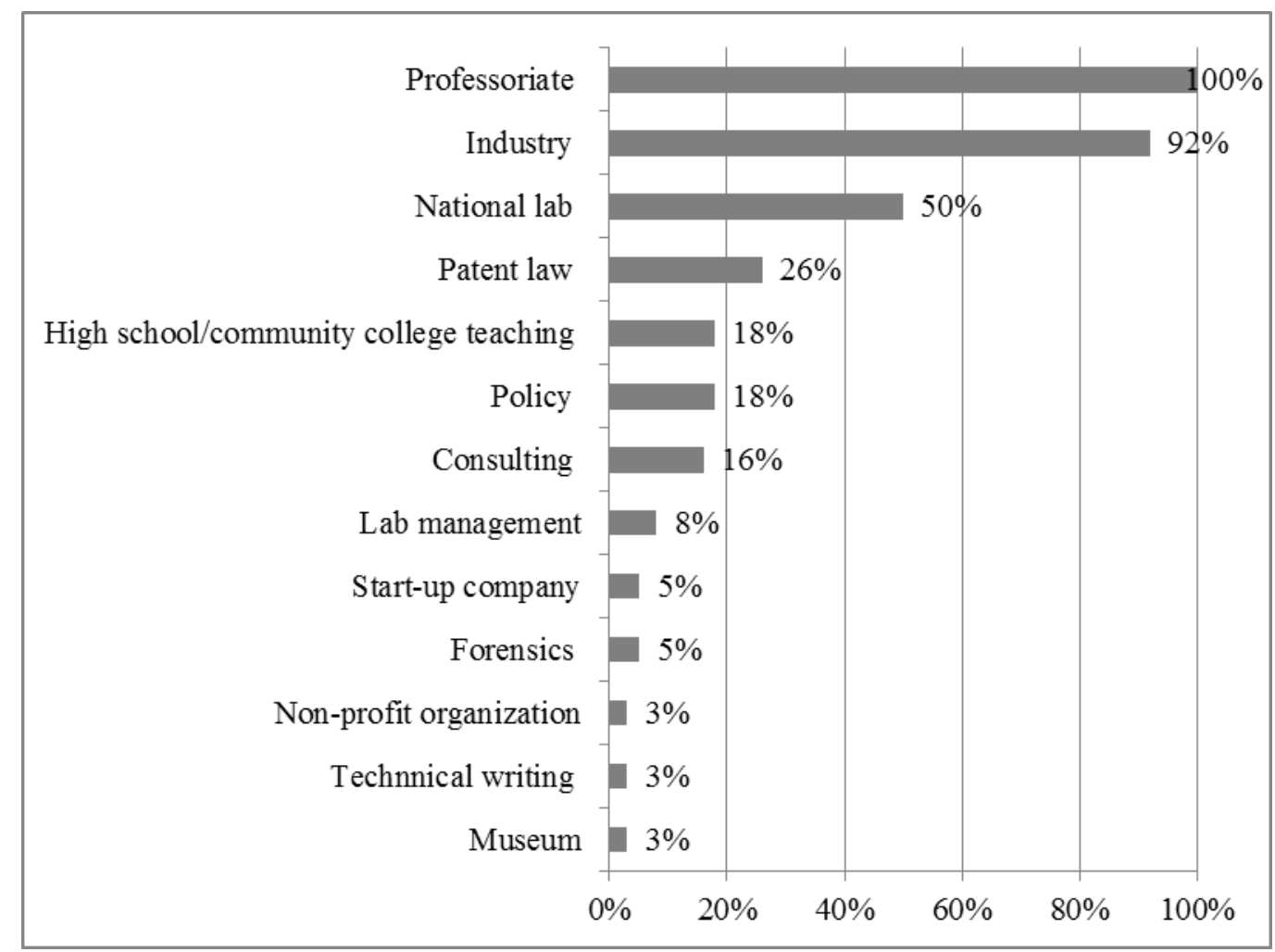

Figure 1. Doctoral students' awareness of career paths (percentage of individual interviewees, $n=44$ )

Our interviews with students demonstrated that while many knew of basic career options for chemists, such as professor or industry researcher, most had little knowledge of specific career paths beyond those two fundamental options. Awareness of academe and industry was nearly universal: $100 \%$ of students mentioned academe as a possible path, and $92 \%$ of students noted industrial career paths. However, knowledge of potential careers fell sharply from there. Only $50 \%$ of students mentioned US government research labs and $26 \%$ mentioned patent law. Fewer than $20 \%$ noted careers in policy or consulting, or other "alternative" career options, such as 
technical writing. In the most worrisome cases, a few interviewees lacked awareness of careers that were appropriate for their educational level. In fact, about $10 \%$ of late-stage students expressed interest in careers which did not require a graduate degree, most frequently forensic science careers that often require only an undergraduate degree, as noted in the following statement from a late-stage student.

There's always been some fields of chemistry that have interested me but I don't know if it would really take a PhD to do them. Like food chemistry, I've always found to be intriguing, and forensic science. But the more and more people you talk to about it, they're like, 'You can pretty much do that with a bachelor's level degree. You don't need a doctorate to do forensic science.'

Students showed limited understanding of professional work responsibilities and lifestyles, even for careers that they knew were possibilities for doctoral chemists. Industry is the most common career path for chemists (ACS, 2010) and was a widely recognized path in our study, but not well understood by students. Students reported that they had little conception of what their future work life might be like in industry or how to best prepare for such a career during graduate school. They also did not know about industry career tracks - such as choices of management versus research positions - or differences among company types or sizes. Additionally, only 5\% of students reported that they had actually tried out industry research through an internship experience. In a focus group interview, an early-stage student described the lack of opportunity to learn about the nature of work in industry careers.

I actually kind of want to go towards industry. I'm not sure if I'd want it to be a pure research experience, but I'm not sure about what other opportunities are available. I definitely want an opportunity at some point to see what industry is all about. Because you just hear industry all the time, and I don't really know what that entails.

A contributor to this lack of career information and awareness was students' limited access to role models. Students had role models in academe, but lacked professional models in other careers. The following comment is representative of many students, both early- and late-stage, contrasting their abundant access to role models within academe to their limited access to industry role models.

Of course there's academia, you see it, because that's what everybody you're learning from has done. Beyond that, I've picked up a little bit on industry. No one's ever really said what industry is. Even today I still haven't had anybody sit down and say what "industry" for a chemist is. They just say, 'It's industry, it's that other thing that chemists do besides going into academia.'

A sizable minority, nearly $40 \%$ of late-stage students, expressed interest in learning more about or pursuing the so-called "alternative" career paths for scientists, those outside industry research or the professoriate. Many of these students had decided that they did not want to focus on research in their careers, but they were uncertain as to how they might use their degrees. For example, a late-stage student described her professional path: she had decided she did not want to be a bench chemist and she was interested in communicating science to lay people, yet she lacked specific information about the potential careers in which she could use that skill. Consequently, she attempted to explore a variety of career paths without real knowledge of what those paths entailed and whether they would be a good fit for her skills and interests. She described this chaotic process of exploring potential careers during the job search process.

I'm still kind of trying to figure out [what to do after graduate school]. I've come to realize that I probably don't want to be a bench chemist if I can avoid that, so 
I've been looking at alternatives. I interviewed with a consulting firm last year. I'm currently trying to apply for potential government positions. I've looked at law firms - I'm kind of open. But I realize I want to be the go-to scientist for someone who's not a scientist.

Students generally learned about the professoriate by drawing on their faculty networks and observing their doctoral research advisor. But students with other career interests had difficulty exploring career paths where they had no social connections. An early-stage student remarked:

I think everyone kind of sees it, we know what it looks like to be an R1 professor [i.e., in a research-extensive university]. Those of us who went to small liberal arts colleges know kind of what it looks like to do that. But not very many of us know what's it like in industry. Or in a national lab. Or, working in the policy side of things, or it's hard to see how to do that. How to-'Okay, I have a Ph.D., I don't want to do this anymore - how do I get from here to there?'

Unlike their peers, a few students $(\mathrm{n}=6)$ with "alternative" professional interests had a more advanced understanding of their future career paths, primarily because they were able to cultivate developmental networks in these careers. As an example, four late-stage students conveyed interest in non-tenure-track faculty positions that they had discovered through their research or teaching work in graduate school. One student recounted how she had consulted with a lab manager who was an expert in crystallography for her dissertation research. Subsequently, she became interested in this type of position as a future career. Through her interactions with the crystallographer, she learned about the work responsibilities and lifestyle of a lab manager.

Short-term connections could also be influential for students interested in alternative careers, at least in terms of exposing students to career possibilities. A late-stage student described the process of learning serendipitously about policy careers from a science policy expert who gave a talk in her department.

So [the speaker] was here giving a talk, and he works in D.C. as a science advisor. I was like, 'Science policy? Who even knew? That's really interesting.' So I've started paying attention more now to the options that are available I think, 'cause that time is nearing.

However, these short-term connections did not always offer students the depth of understanding about the nature of practice in alternative careers provided by long-term relationships with professional role models.

\section{The Range of Students' Developmental Networks}

To address their gaps in career knowledge, students drew on many sources of information, with varying degrees of success. In interviews, we asked students where they had learned about doctoral career paths in their field. Figure 2 details the percentage of individual student responses naming specific sources of career information.

Students' most common source of career information was peers. Our data suggest that students primarily learned about future professional roles from observing their peers in the job search process - peers who probably gained their own career information in the same way. A student described the "word of mouth" process of learning about careers through peer networks, noting that it was not a helpful process for learning about industry and non-academic careers.

Industry. That would probably be the career that I've had the least exposure to. While I've heard of a few people that have gone into industry and do different things, I haven't really sat down and talked with them about what they're doing, 
mostly just because they are several years older than me and kind of work in their jobs out there. It's more of just by word of mouth, I hear, 'Oh, so and so is working at this company now and they just got promoted to group manager.'

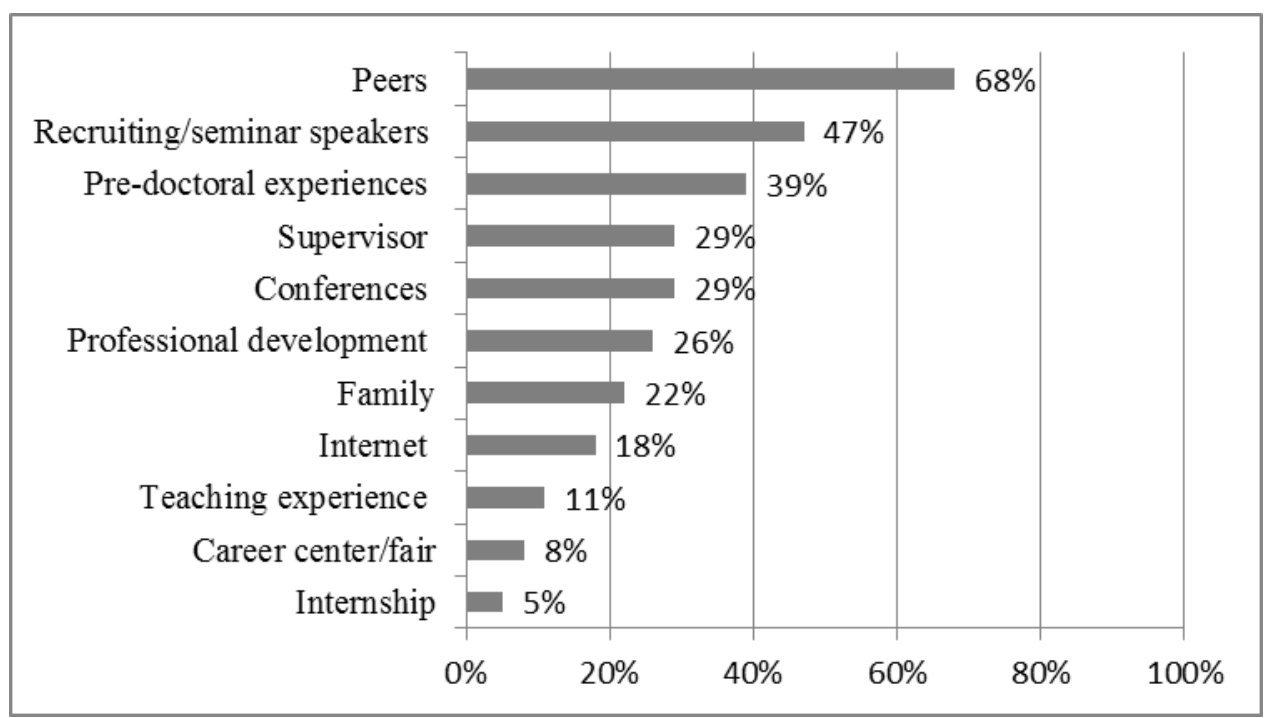

Figure 2. Sources of career information for Ph.D. students (percentage of individual interviewees, $n=44$ )

In addition to their peers, students drew on other sources of career information. Nearly half of students mentioned that they learned about careers from opportunities provided by their departments, such as seminar speakers or recruiting talks by industry representatives. For instance, a late-stage student commented on how he had learned about career possibilities from speakers in a departmental workshop series.

The department's career enhancement series, they show you the options. They bring in industry people who talk about industry. They'll bring in outside academic people to talk about academics. They'll bring in someone from a government lab to talk about government positions. So, that really helped clarify the pros and cons of each position from people on the inside.

Although each campus had a career development office, few students reported that they had used this campus resource. Ironically, a student on one campus reported that she had never used the campus career office because she hadn't known any other students to use it.

To some extent, programming that supplemented students' research and coursework helped to partially fill the gaps in students' limited knowledge of careers. Two campuses in our study had active and long-standing Preparing Future Faculty (PFF) programs (Gaff, 1994) and all three departments held career seminars and occasional skill-building workshops. Additionally, some students received mentoring or training at conferences. Still, departmental, professional society, and institutional career resources were often targeted toward careers in academe, or to a lesser extent, industry. These offerings were also underutilized by students, as only one quarter of students reported they had participated in such professional development opportunities. Nevertheless, professional development opportunities were beneficial for students interested in the professoriate, developing students' pedagogical skills and knowledge, and introducing them to career opportunities they were unaware of or had not considered, such as community college teaching.

Nearly a quarter of students mentioned that they drew on familial networks for information about working in scientific fields. But students with no familial role models were more likely to be ill- 
informed about professional roles in the sciences. Gender did not play a role in access to familial role models. However, underrepresented minority students and those who had been the first in their family to go to college reported less awareness of career options. In part, these differences stemmed from variability in students' access to familial networks that are connected to science. For instance, nine out of $34(26 \%)$ Caucasian interviewees reported that their parents in scientific or academic careers were a source of learning about doctoral careers, while only one out of nine underrepresented minority late-stage students $(11 \%)$ discussed familial role models in science. Students without familial networks had less information about science careers, as suggested by the following comment.

I have no idea [about career options]. (LAUGHS) I have no clue. Which is scary. Because I don't really know anyone... that has a $\mathrm{PhD}$ in chemistry, other than the people around here. I don't know anyone in like "the real world" with a chemistry $\mathrm{PhD}$, or like any of my parent's peers that I could talk to about it. So, I have no idea what to expect.

Doctoral advisors are often thought to be students' most important source of career information, yet in this study, they were the fourth most frequent source of career information for students, with high variability in the quality and utility of this advice. Less than one third of students reported that they learned about careers from their current advisor. Students often did not seek information from their advisors because they perceived them to be unhelpful for their career development. Indeed, nearly one third of students commented that their advisors were unsupportive of any professional activities that took them away from research. These students often felt uncomfortable discussing such opportunities with their advisors and did not feel that they were "allowed" to participate in them. For example, one student had identified a summer industry internship opportunity in Europe that fit her professional interests and goals, yet her doctoral advisor required her to stay in his lab over the summer. Other students described trepidation in telling their advisors about their desire to participate in professional development opportunities for fear that their advisor would not consent to their participation.

Those in our study who did receive career information from their advisors found them to be helpful, supportive, and influential to their career preparation. In the following comment, an earlystage student described her advisors' interest in her career goal of government research, contrasting him with other, less-supportive advisors in her department.

When I started working with him, one of his first questions, was, 'Well, what are you interested in doing in the future?' Because he's definitely interested in preparing us for wherever we wanna go, and he knows where I wanna go, and he's very supportive of that. And we just talked about it again about a month ago, because he was trying to set up the whole internship thing for me. He's good at introducing us to people that he thinks will help us along the way. He's very supportive of going to conferences, which is nice. Because, again, some advisors won't do that because they think it's a waste, because you're gone for a week from the lab.

Although some interviewees learned about career choices from their doctoral advisors, many in this group of students still did not observe their advisors in all of their multi-faceted roles as faculty member and scientist. Similar to Austin's (2002) findings, students reported that many aspects of the professoriate were unclear to them, including grant writing, committee and service work, and other governance or entrepreneurial functions of the faculty role, as described in the following comment.

I see a little bit of [the life of a professor] although I kinda see [my advisor] as an in-between kinda guy, 'cause he does have businesses that he runs, and he also 
has the lab at the university, and so he's a little bit everywhere. And so, of course, I don't really observe him, and it might be a good idea, to try to observe him in his role as the administrator of his business versus his role in our group meetings when he's working with his grad students. Maybe that's a good idea, but, I really don't know exactly how it works for a PhD at that level, between academia and industry.

In conclusion, students reported that peers were their most frequent source of career information, especially observing peers during the job search process. Against common wisdom of many in academe, students relied on their advisors for career information to a much lesser extent than on peers.

\section{The Role of Agency in Students' Career Planning}

Late-stage students often had one of two polarized reactions to their lack of knowledge about career options, either anxiety or apathy. For instance, a student who was very active in scientific presentation and professional networking to advance her scientific research expressed concern about her lack of career awareness. Her comment was typical of statements from students who had successfully navigated graduate school and achieved its major milestones, yet who were clearly anxious about their lack of understanding of career paths for doctorates.

It's all sort of a black hole. Which as I get closer and closer to writing my thesis and graduating, I feel like the black hole is gonna swallow me.

Anxious students were more likely to engage in career exploration activities than apathetic students, yet they often did so in an incoherent or haphazard way as demonstrated by the earlier description of the student who had pursued a variety of non-academic career options without a coherent plan or real knowledge about those careers.

On the other hand, most students were more apathetic about their lack of knowledge about careers, and thus delayed career preparation and selection until near or after graduation. Many of these students planned to pursue temporary postdoctoral research opportunities without a rationale for how these positions may advance their career or fit into a career trajectory. The following comment from a student within a year of graduation is representative of the perspective of these students who felt no urgency to prepare for careers until the end of graduate school.

I don't know tons, but I know there's plenty of options in academia, industry, government work. I dunno. There's kind of a lot out there. I haven't gotten to the point yet where I'm actively trying to search for jobs, so I'm not quite sure if I know as much as I should.

While some students - mainly those students who had already selected a career - actively and strategically cultivated a wide range of developmental networks and sought information about future careers, nearly two thirds of students reported no systematic strategy for learning about or preparing for careers. Many of the former group were interested in the professoriate or had stumbled upon a desirable "alternative" career in which they were able to cultivate developmental networks and had clearly charted a course toward achieving their goals. On the other hand, many of the latter group of non-systematic students did not rely on personal, developmental networks at all in their career selection process and looked to the internet or departmental emails for information. However, these distant and fleeting connections did not allow students to learn about more nuanced details of these career paths, as noted in the following comment from a late-stage student.

I [learned about careers] mostly from just looking at the internet and getting information that way. And not from necessarily talking to other people. Like if you 
go to Science or ACS [the American Chemical Society], their websites have career sections. There's a lot of information there [about academic careers]. There's some information about different career paths if you want to be in industry. I haven't seen anything really specific about that or a large amount of information.

Thus, the majority of students did not have a clear and coherent strategy for learning about career choices and were not lucky enough to stumble on the right option. Consequently, most students put off the career preparation process until the end of graduate school and then made frantic efforts to prepare themselves for a career as they approached graduation. A faculty member observed:

Do I think students could be better informed? Absolutely. Do I think it's partly their fault? Absolutely... The analogy is everybody's cramming for exams. How do you get people to not cram for exams, and put a little time in for reflection so that they can ask the next question before the exam comes?

In conclusion, students' professional preparation was often hampered by a lack of knowledge about career possibilities. In particular, students lacked knowledge and access to role models for the array of non-academic careers available to doctoral scientists.

\section{Discussion and Implications}

Calls for reform in doctoral education over the past few decades have focused on students' lack of preparation for careers (Golde \& Dore, 2001; Nerad et al., 2006; Nyquist, 2002; Taylor, 2006; Wendler et al., 2012), often citing a dearth of training opportunities in teaching, communication, and other essential skills. In this study, departments, institutions, and professional organizations provided some supplemental opportunities for doctoral students to learn about careers and develop non-scientific skills. But our study has uncovered other factors underlying students' general lack of preparedness for life and work after graduate school. Career and skill-building workshops, seminars and other professional development opportunities are only meaningful to students if they have a broad knowledge of the types of careers available to doctorates and an understanding of the skills, attitudes, and behaviors required in those careers. When students lacked this foundational understanding of potential career options, they either did not pursue available opportunities, or they overloaded themselves with a haphazard assortment of trainings and activities that often left them no further along the career decision-making path than when they started. Therefore, doctoral students' career development must begin with a firm knowledge and understanding of the variety of careers suitable for doctorates in their field.

This study also challenges the taken-for-granted notion that doctoral advisors are, and should be, students' most important source of career development. These types of taken-for-granted practices are structured into doctoral education without evidence of their outcomes or effectiveness (McAlpine \& Amundson, 2012). For one, advisors are often unaware of the importance of peers and informal socialization in doctoral students' professional development (Gardner, 2010b). Indeed, our data affirm that students drew on a broad range of developmental networks to learn about and prepare for careers, in both positive and negative ways. Rather than depend solely on their advisor for career information, many students cultivated a range of developmental networks for career guidance, including peers or short-term connections from professional development seminars or workshops. Yet students often constructed these networks in a disorganized and unhelpful way as there was no systematic process for them to learn about potential careers and to build the requisite skills to succeed in the workforce.

Recent research has highlighted the significant role that peers play in doctoral students' developmental networks (Jazvac-Martek, Chen, \& McAlpine, 2011). Similarly, our data indicate that stu- 
dents often turned to their peers for career information-yet these peers were largely unaware and uninformed themselves, especially about the so-called "alternative" careers. Given the lack of systematic sources for students' career development, the void was often filled by rumor, hearsay, and word of mouth from peers. Thus, a cycle of misinformation perpetuated itself as students had no clear way to develop the wide range of networks that they needed to prepare for careers. Additionally, students differed in their interest in and ability to cultivate helpful developmental networks that extended beyond their advisor and peers. If students were unable to learn about and try out possible selves, they did not feel that developing an array of professional networks was a useful endeavor for them, and they simply delayed the career preparation process. Students without familial or prior role models in the sciences - often underrepresented minority students or those who had been the first in families to earn an undergraduate degree - had an even greater need for explicit career information.

Students' lack of awareness about careers and their subsequent under preparation was confounded by the perceptions of a sizeable minority of students that their advisor was unsupportive of their career exploration, particularly for non-academic careers. These perceptions were often grounded in the belief that the advisor "needed" the student for his or her own research work and would not permit the student to seek supplemental opportunities. Lack of advisor support may be particularly detrimental to students interested in preparing for non-academic careers because advisors and general departmental cultures often value academic careers over teaching or administrative careers (Baker \& Pifer, 2014; Thiry et al., 2007). In this respect, our findings support the recommendation in a recent American Chemical Society report that graduate student funding should be decoupled from faculty research grants (ACS, 2012). The current US model of funding for STEM graduate education through grants to faculty to support graduate research assistants privileges the need for faculty research productivity over doctoral students' educational needs and creates organizational contexts that can impede students' access to professional preparation opportunities.

Clearly, the majority of students in this study had only partial knowledge of the range of career paths available to doctoral chemists. They were also unable to observe role models in potential careers, with the exception of the role of professor in a research university, and thus most students lacked basic knowledge of non-traditional careers, such as scientific policy expert, entrepreneur, or consultant. The few students who had selected and were actively preparing for alternative careers had stumbled upon these options by happenstance, rather than through a thoughtful career development process. Without the opportunity to observe or interact with practicing professionals, especially in "alternative" careers, students were unable to learn about and prepare for these careers and, thus, try out possible selves.

Our findings highlight several reform efforts that should be undertaken within scientific doctoral education. First, students are ultimately responsible for their own career paths, and they must actively pursue a variety of networks and role models to allow them to try out possible selves. Our data suggest that developmental networks do not have to be intensive or extended in scope or duration to be helpful to students. Short-term connections fostered through workshops and seminars helped students to learn about the variety of career possibilities and to consider various options for fit, though in a limited way. However, students must seek out and participate in these opportunities.

For departments and institutions, our data highlight the importance of systematically expanding professional learning opportunities so that students are exposed to career paths and provided with information about the knowledge and skills required in those careers. O'Meara and colleagues (2014) described steps that departments can take to augment students' agency in career advancement, such as encouraging multiple career paths, providing supplemental learning opportunities, providing information resources, and facilitating networking and mentoring. In this study, departments, institutions. or professional societies had undertaken some of these career develop- 
ment activities, such as offering career workshops, seminars, and guest speakers. Nevertheless, our informants noted that these forums were not as well attended as they could have been, and many students claimed that they did not know about them. Additionally, many of these opportunities were geared for academic paths. Instead, these opportunities should span the spectrum of career paths and be provided in a variety of venues. These valuable opportunities must be creatively marketed to students and advisors and students should be encouraged to take advantage of these short duration, yet informative, opportunities.

Career exploration needs to begin earlier than the late-stage scramble that we so often encountered in this study. All students should be encouraged early in their studies to cultivate a range of developmental networks and pursue a variety of opportunities to learn about careers and to build professional skills. Students and faculty should view these trainings as integral to doctoral education. Observing peers in the job search process may be helpful in some ways, but students must look beyond their peers if they are to be fully informed and prepared to choose among the breadth of $21^{\text {st }}$-century scientific careers. Developmental networks that fostered long-term relationships and interactions between students and practicing professionals were most beneficial. However, because peers are such an important source of support for doctoral students, outcomes from these developmental networks might be improved if interested students received training in careerfocused peer mentoring or if recent alumni were recruited to share career information with current students.

While students certainly need to take a more strategic approach to their own professional preparation, doctoral educators and others invested in the future scientific workforce surely bear some responsibility for assisting this process. Doctoral education should be a time for exploring a variety of professional roles. Our findings suggest that students need a wide range of networks, beyond peer and advisory relationships, to learn about and try out the full array of possible selves available to them. Professional opportunities, including access to professional networks, must be more purposefully and systematically integrated into doctoral education throughout students' graduate careers.

Our findings help to explain some of the reasons behind the gap between graduate preparation and professional workforce needs that has been described by other researchers. While other scholars have identified the existence of this gap (American Association of Universities (AAU), 1998; Golde \& Dore, 2001; Nerad et al., 2006; Nyquist, 2002; Taylor, 2006; Wendler et al., 2012), we have documented some of the interactions and processes that underlie the mismatch. In particular, we have articulated the role of developmental networks (or lack thereof) and other sociocultural factors in exacerbating students' lack of professional readiness. Our findings suggest that improved doctoral career preparation will depend on the actions of graduate students, faculty and departments alike. These lessons should apply widely across science and other disciplines.

\section{Acknowledgement}

This research was supported by the National Science Foundation under Award DRL-0723600. All assertions are those of the authors and not of the National Science Foundation.

\section{References}

American Association of Universities (AAU), (1998). AAU Committee on Graduate Education: Report and recommendations. Retrieved on 3/9/10 from http://www.aau.edu/WorkArea/DownloadAsset.aspx?id=6720

American Association of University Professors (AAUP), (2011). It's not over yet: The annual report on the economic status of the profession, 2010-2011. Retrieved on 10/3/12 from http://www.aaup.org/NR/rdonlyres/17BABE36-BA30-467D-BE2F-34C37325549A/0/zreport.pdf 
American Chemical Society (ACS). (2010). Research brief: U.S. chemistry employment and unemployment: Data, implications, and trends. Washington, DC: American Chemical Society.

American Chemical Society (ACS). (2012). Advancing graduate education in the chemical sciences: Summary report of an ACS presidential commission. Washington, DC: American Chemical Society.

American Chemical Society (ACS). (2014). 2013 ACS graduate student survey. Washington, DC: American Chemical Society.

Antony, J. S. (2002). Reexamining doctoral student socialization and professional development: Moving beyond the congruence and assimilation orientation. Higher Education: Handbook of Theory and Research, 17, 349-380.

Austin, A. E. (2002). Preparing the next generation of faculty: Graduate school as socialization to the academic career. The Journal of Higher Education, 73(1), 94-122.

Austin, A. E., \& McDaniels, M. (2006). Preparing the professoriate of the future: Graduate student socialization for faculty roles. Higher Education: Handbook of Theory and Research, 21, 397-456.

Australian Government. (2012). Job outlook: An Australian Government initiative. Retrieved on 03/20/13 from http://joboutlook.gov.au/pages/default.aspx

Baker, V. L., \& Lattuca, L. R. (2010). Developmental networks and learning: Toward an interdisciplinary perspective on identity development during doctoral study, Studies in Higher Education, 35(7), 807827

Baker, V. L., \& Pifer, M. J. (2014). Preparing for practice: Parallel processes of identity development in stage 3 of doctoral education. International Journal of Doctoral Studies, 9, 137-154. Retrieved from http://ijds.org/Volume9/IJDSv9p137-154Baker0623.pdf

Bieber, J. P., \& Worley, L. K. (2006). Conceptualizing the academic life: Graduate students' perspectives. Journal of Higher Education, 7(6), 1009-1035.

Bouwma-Gearhart, J., Millar, S., Barger, S., \& Connolly, M. (2007). Doctoral and post-doctoral STEM teaching-related professional development: Effects on training and early career periods. Paper presented at the annual meeting of the American Educational Research Association (AERA), Chicago, IL, April 9-13, 2007.

Bureau of Labor Statistics (BLS). (2012). Occupational outlook handbook. Retrieved on 03/20/13 from http://www.bls.gov/ooh/life-physical-and-social-science/home.htm

Caserio, M., Coppola, B. P., Lichter, R. L., Bentley, A. K., Bowman, M. D., Mangham, A. N., Metz, K. M., Pazicni, S., Phillips, M. F., \& Seeman, J. I. (2004). Responses to changing needs in U.S. doctoral education. Journal of Chemical Education, 81, 1698-1703.

Connolly, M. R. (2011). Helping future faculty "come out" as teachers. Essays on Teaching Excellence, Vol. 22. Retrieved on 09/15/14 from http://podnetwork.org/content/uploads/V22_N6 Connolly.pdf

Council for Chemical Research. (2011). Council for Chemical Research CTO roundtable for graduate education. Washington, DC: Council for Chemical Research. Retrieved on 09/15/14 from http://archiveorg.com/page/4106471/2014-06-10/http://www.ccrhq.org/

Cyranoski, D., Gilbert, N., \& Ledford, H. (2011). The PhD factory: The world is producing more PhDs than ever before. Is it time to stop? Nature, 472, 276-279.

Denzin, N. K. (1978). The research act: A theoretical introduction to sociological methods. New York: MacGraw-Hill.

Dobrow, S. R., Chandler, D. E., Murphy, W. M., \& Kram, K. E. (2012). A review of developmental networks: Incorporating a mutuality perspective. Journal of Management, 38(1), 210-242.

Dobrow, S. R., \& Higgins, M. C. (2005). Developmental networks and professional identity: A longitudinal study. Career Development International, 10(6/7), 567-583. 
European Commission. (2012). Draft joint employment report. Retrieved on 3/20/13 from http://ec.europa.eu/europe2020/pdf/ags2013 emplr en.pdf

Fox, M. F. \& Stephan, P. E. (2001). Careers of young scientists: Preferences, prospects, and realities by gender and field. Social Studies of Science, 31(1), 109-122.

Gaff, J. G. (1994). Faculty development: The new frontier. Liberal Education, 80, 16-21.

Gardner, S. K. (2007). "I heard it through the grapevine": Doctoral student socialization in chemistry and history. Higher Education, 54, 723-740.

Gardner, S. K. (2010a). Contrasting the socialization experiences of doctoral students in high- and lowcompleting departments: A qualitative analysis of disciplinary contexts at one institution. The Journal of Higher Education, 81(1), 61-81.

Gardner, S. K. (2010b). Faculty perspectives on doctoral student socialization in five disciplines. International Journal of Doctoral Studies. 5, 39-53. Retrieved from http://ijds.org/Volume5/IJDSv5p039053Gardner293.pdf

Golde, C. M. (2008). Applying lessons from professional education to the preparation of the professoriate. New Directions for Teaching and Learning, 113, 17-25.

Golde, C. M. \& Dore, T. M. (2001). At cross purposes: What the experiences of today's doctoral students reveal about doctoral education. Report prepared for The Pew Charitable Trusts: Philadelphia, PA.

Higgins, M. C., \& Kram, K. E. (2001). Reconceptualizing mentoring at work: A developmental network perspective. The Academy of Management Review, 26(2), 264-288.

Hopwood, N. (2010). A sociocultural view of doctoral students' relationships and agency. Studies in Continuing Education, 33(2), 103-117.

Ibarra, H. (1999). Provisional selves: Experimenting with image and identity in professional adaptation. Administrative Science Quarterly. 44(4), 764-791.

Janke, E. M., \& Colbeck, C. L. (2008). Lost in translation: Learning professional roles through the situated curriculum. New Directions for Teaching and Learning, 113, 57-68.

Jazvac-Martek, M., Chen, S., \& McAlpine, L. (2011). Tracking the doctoral student experience over time: Cultivating agency in diverse spaces. In L. McAlpine and C. Amundsen (Eds), Doctoral education: Research-based strategies for doctoral students, supervisors, and administrators. New York: Springer.

Kuck, V. J., Marzabadi, C. H., Buckner, J. P., \& Nolan, S. A. (2007). A review and study on graduate training and academic hiring of chemists. Journal of Chemistry Education, 84(2), 277-284.

Kwiram, A. L. (2006). Time for reform? In C. M. Golde \& G. E. Walker (Eds.), Envisioning the future of doctoral education: Preparing stewards of the discipline. Carnegie essays on the doctorate (pp. 141166). San Francisco: Jossey-Bass.

Laursen, S. L., Thiry, H., \& Liston, C. (2012). The impact of a university-based school science outreach program on graduate student participants' career paths and professional socialization. Journal of Higher Education Outreach and Engagement, 16(2), 47-78.

Lave, J., \& Wenger, E. (1991). Situated learning: Legitimate peripheral participation. Cambridge: Cambridge University Press.

Loshbaugh, H. G., Laursen, S. L., \& Thiry, H. (2011). Reactions to changing times: Trends and tensions in U.S. chemistry graduate education. Journal of Chemical Education, 88(6), 708-715.

Merriam, S. B. (2009). Qualitative research: A guide to design and implementation. San Francisco: JosseyBass.

McAlpine, L., \& Amundsen, C. (2012). Challenging the taken-for-granted: How research analysis might inform pedagogical practices and institutional policies related to doctoral education. Studies in Higher Education, 37(6), 683-694. 
McAlpine, L., \& Lucas, L. (2011). Different places, different specialisms: Similar questions of doctoral identities under construction. Teaching in Higher Education, 16(6), 695-706.

National Center for Education Statistics (NCES). (2011). Digest of education statistics, 2011. (NCES 20011-022). Washington, D.C.: National Center for Education Statistics, Institute of Education Sciences, U.S. Department of Education.

National Science Board (NSB). (2012). Science and engineering indicators 2012. Arlington, VA: National Science Foundation (NSB 12-01).

Nerad, M., Rudd, E., Morrison, E., \& Homer, L. (2006). Confronting common assumptions: Designing future-oriented doctoral education. Proceedings of Doctoral Education and the Faculty of the Future, Cornell University, Ithaca, NY, October 8-9, 2006.

Neumann, R., \& Tan, K. K. (2011). From PhD to initial employment: The doctorate in a knowledge economy. Studies in Higher Education, 36(5), 601-614.

Nyquist, J. (2002). The Ph.D.: A tapestry of change for the 21st century. Change, 34(6), 13-20.

O’Meara, K., Jaeger, A., Eliason, J., Grantham, A., Cowdery, K., Mitchall, A., \& Zhang, K. (2014). By design: How departments influence graduate student agency in career advancement. International Journal of Doctoral Studies, 9, 155-179. Retrieved from http://ijds.org/Volume9/IJDSv9p1551790Meara0518.pdf

Sauermann, H., \& Roach, M. (2012). Science PhD career preferences: Levels, changes and advisor encouragement, PLoS ONE, 7: 36307. doi:10.1371/journal.pone0036307

Schensul, S. S., Schensul, J. J., \& LeCompte, M. D. (1999). Essential ethnographic methods: Observations, interviews, and questionnaires. Walnut Creek, CA: Altimira Press.

Spradley, J. P. (1980). Participant observation. Fort Worth: Harcourt Brace College Publishers.

Stevens, R., O'Connor, K., Garrison, L., Jocuns, A., \& Amos, D. M. (2008). Becoming an engineer: Toward a three dimensional view of engineering learning. Journal of Engineering Education, 97(3), 355368.

Suresh, S. (2011). Basic research generates jobs and competiveness. Science News, March 26.

Sweitzer, V. B. (2009). Towards a theory of doctoral student professional identity development: A developmental networks approach. The Journal of Higher Education, 80(1), 1-33.

Taylor, C. (2006). Heeding the voices of graduate students and postdocs. In C. M. Golde \& G. E. Walker (Eds.), Envisioning the future of doctoral education: Preparing stewards of the discipline. Carnegie essays on the doctorate (pp. 46-54). San Francisco: Jossey-Bass.

Thiry, H., Laursen, S. L., \& Liston, C. (2007). (de)Valuing teaching in the academy: Why are underrepresented graduate students overrepresented in teaching and outreach? Journal of Women and Minorities in Science and Engineering, 13(4), 391-419.

Wendler, C., Bridgeman, B. Markle, R., Cline, F., Bell, N., McAllister, P., \& Kent, J. (2012). Pathways through graduate school and into careers. Princeton, NJ: Educational Testing Service. 


\section{Biographies}

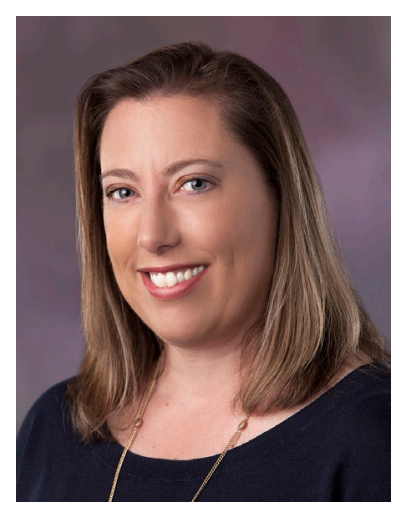

Heather Thiry, Ph.D. is a Research Associate with Ethnography \& Evaluation Research at the University of Colorado, Boulder. For over a decade, Thiry has conducted educational research and external program evaluation of STEM education innovations from the K-12 through the graduate education levels. Her research interests focus on the educational and career pathways of students from groups traditionally underrepresented in scientific and technological fields. She also focuses on informal learning environments, social justice in STEM education, and organizational climate. She is currently co-PI of a national, mixed-methods research study exploring student persistence in STEM undergraduate degrees. She received her Ph.D. in Educational Foundations, Policy, and Practice.

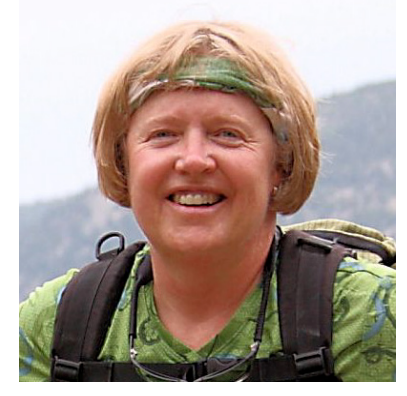

Sandra Laursen, Ph.D., is senior research associate and co-director of Ethnogra phy \& Evaluation Research (E\&ER) at the University of Colorado Boulder (www.colorado.edu/eer ), where she leads research and evaluation studies focusing on education and career paths in science, technology, engineering, and mathematics (STEM) fields. Particular research interests include the underrepresentation of women and people of color in the sciences, professional socialization and career development of scientists, teacher professional development, and organizational change in higher education. She is also interested in inquiry-based teaching and learning, and the challenges of improving STEM education in and out of the classroom.

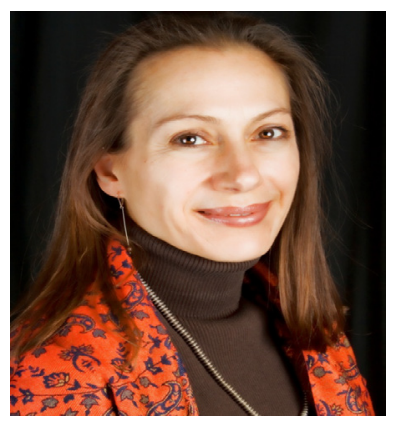

Heidi G. Loshbaugh, Ph.D. is the Dean for the Center for Math and Science at the Community College of Denver (CCD). She is responsible for operations in science and mathematics courses, working with students, faculty, and staff. Prior to joining CCD in 2011, Dr. Loshbaugh was on a research team at University of Colorado Boulder, conducting National Science Foundation-funded research on the professional preparation of doctoral chemistry students and the implementation of science education reform at CU. She also spent eleven years at Colorado School of Mines, where she served as classroom faculty, research faculty, and the institution's first Special Advisor to the President, for Diversity. 